\title{
Anaesthetic Considerations During Laparoscopic Surgery
}

\author{
Maria F. Martín-Cancho, Diego Celdrán, \\ Juan R. Lima, Maria S. Carrasco-Jimenez, \\ Francisco M. Sánchez-Margallo and Jesús Usón-Gargallo \\ Minimally Invasive Surgery Centre Jesus Usón, \\ Spain
}

\section{Introduction}

Laparoscopic surgery has improved greatly during the last years, mainly thanks to advances in both anaesthetic and surgical techniques (Llagostera-Pujol et al., 2002). Abdominal laparoscopy is normally perceived to be associated with few risks. However, clinicians should be aware of inherent dangers such as gaseous embolism, a potential inability to control haemorrhage, an increase in carbon dioxide arterial partial pressure, and changes in arterial blood pressure and heart rate. The hemodynamic and respiratory alterations associated with abdominal laparoscopy are caused by the high intraabdominal pressure brought over by pneumoperitoneum creation. The most relevant hemodynamic changes are a decrease in venous return secondary to Inferior Vena Cava compression and increases in central venous pressure and arterial blood pressure in absence of heart rate changes. Regarding respiratory adjustments, cranial displacement of the diaphragm causes a restrictive respiratory syndrome with decreased pulmonary compliance and increased pulmonary pressures and inspiratory peak (Carrasco et al., 1998; Joris et al., 1999).

Anesthesia in laparoscopic procedures it's complicated by the pathophysiologic changes developed because of the pneumoperitoneum creation and the required positioning of the patient. It's also considered a potentially high risk procedure because of other inherent conditions: The duration of procedures is usually longer, there is a risk of visceral injury and it's difficult to estimate the amount of blood loss when hemorrhage occurs.

The anesthesiologist must have a deep understanding of the pathophysiological consequences derived from the pneumoperitoneum, to be prepared to prevent, detect and address the possible alterations that can occur during the intervention.

The physiological changes and complications derived from the pneumoperitoneum are the first topics described. The postoperative benefits of laparoscopy regarding some postoperative aspects will be described in second place. A lot of studies have been published about the advantages and effects of laparoscopic surgeries during the last 35 years, but anaesthetic techniques and laparoscopic conditions have change a lot during the last 15 years, so this review we'll be focused on those modern techniques and conditions. 


\section{Hemodynamic alterations in laparoscopic surgery}

In abdominal laparoscopy procedures, hemodynamic and respiratory alterations are both derived from the same three origins: the first one is the intra-abdominal pressure created by the pneumoperitoneum; the second one is the existence of an insufflation gas that is absorbed by the blood; the third one is the Trendelemburg or anti-Trendelemburg positioning of the patient.

The pneumoperitoneum increases the abdominal pressure, elevates the diaphragm and can compress both small and big blood vessels. The intra-abdominal pressure obtained during these procedures, which is usually $12 \mathrm{mmHg}$ (Fig. 1), increases central venous pressure (CVP), heart rate (HR), systemic vascular resistances (SVR) up to a $65 \%$, and the pulmonary vascular resistances can rise up to a $90 \%$. Cardiac output (CO) can increase on a healthy patient in Trendelemburg position, but can also decrease to a $50 \%$ on patients in antiTrendelemburg position or with a low cardiovascular reserve. All those changes are usually well tolerated in healthy patients but it can be different in patients with systemic diseases.

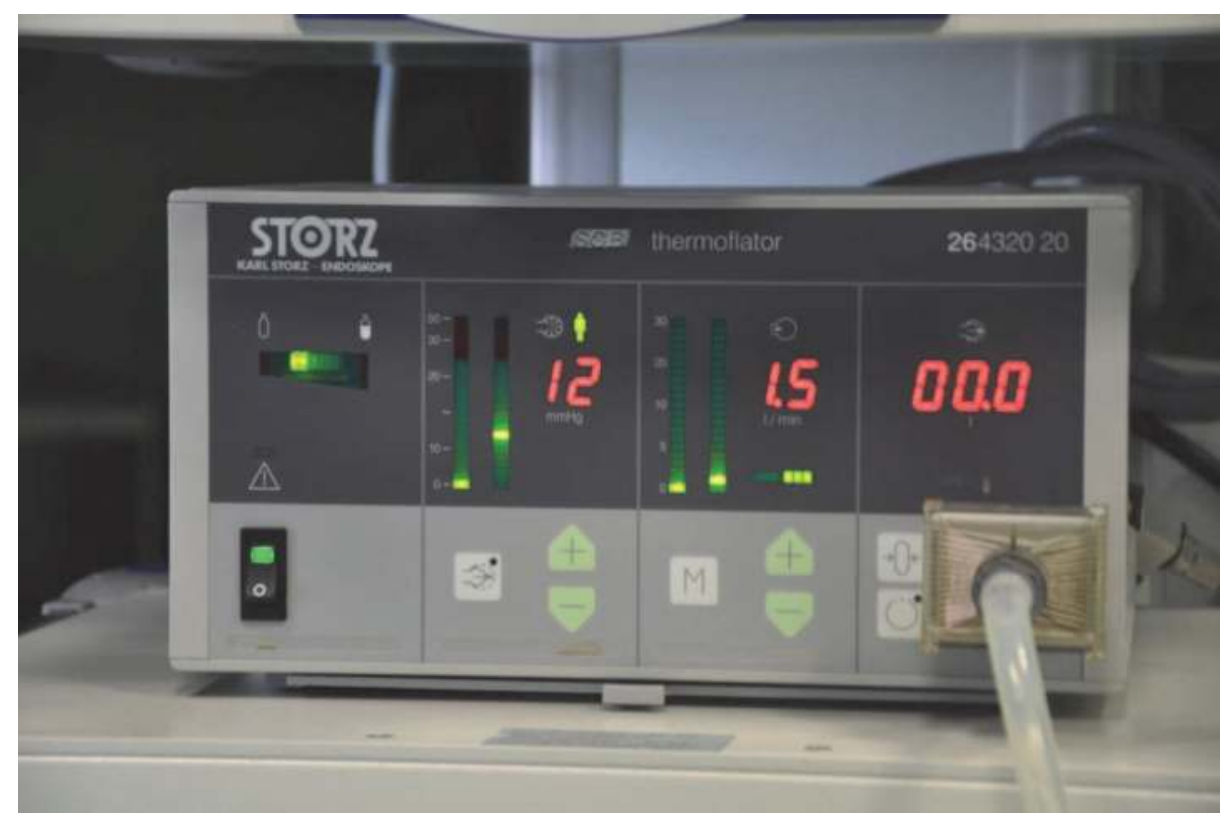

Fig. 1. $\mathrm{CO}_{2}$ Insufflator showing normal working pressure.

When intra-abdominal pressure riches $15 \mathrm{mmHg}$, because of excessive insufflations or because the patient activates the abdominal wall muscles (due to a lack of muscle relaxants that causes an increase of the abdominal wall resistance to the insufflations, cough or tube rejection), a compression of the cava vein can occur, causing a blood return reduction and a decrease in the cardiac output. The diaphragm elevation will raise intra thoracic pressure and will reduce the cardiac output. The lower $\mathrm{CO}$ can be compensated in a healthy patient by increasing the heart rate and arterial pressure, obtaining a stable hemodynamic status; but if an acute hemorrhage occurs, the patient turns fast in to an unstable status. Arrhythmia and bradycardia often appear in non atropinized patients during insufflation. 
All the reported studies describe an increase in systemic vascular resistance during pneumoperitoneum. This increase in afterload can't be considered as a simple sympathetic reflex response to decreased cardiac output (Joris et al., 1993; Cunningham et al., 1993; As cited in Miller's Anesthesia 2005). Systemic vascular resistance also increased in studies in which no decrease in cardiac output was reported (Odeberg et al., 1994; Cunningham et al., 1993; As cited in Miller's Anesthesia 2005). Whereas the normal heart tolerates increases in afterload under physiologic conditions, the changes in afterload produced by the pneumoperitoneum can result in deleterious effects in patients with cardiac diseases and may lead to further decrease in cardiac output (Harris et al., 1996 as cited in Miller's Anesthesia 2005). The increase in systemic vascular resistance is affected by patient position. Whereas the Trendelemburg position attenuates this increase, the head up position aggravates it (Odeberg et al., 1994; Gannedahl et al., 1996; Hirvonen et al., 1995; Hirvonen et al., 1997; As cited in Miller's Anesthesia 2005)

Cardiovascular collapse and asystole cases in healthy patients have been described previously and attributed to deep vagal reflexes due to sudden insufflations.

The carbon dioxide pneumoperitoneum induce the gas absorption leading to a hypercapnia tendency. If pulmonary ventilation is not enough to eliminate the $\mathrm{CO}_{2}$ absorbed from the pneumoperitoneum, then hypercapnia appears and the resultant acidosis can depress myocardial function and predispose to arrhythmia and cardiovascular collapse. Carbon dioxide has also direct effects on the heart; it causes arrhythmia and probably decreases contractibility. It is because of that reasons that Helium has been recommended as insufflation gas in patients with cardiac risk or respiratory disability to eliminate $\mathrm{CO}_{2}$.

Gaseous embolism through an open vessel can produce severe hemodynamic alterations, which can produce a cardiovascular collapse by venous return blockade. Anti-Trendelemburg position increases the severity of the embolism and its repercussions delaying its treatment.

Positioning is essential for the final hemodynamic result during laparoscopy. On superior abdomen procedures, where patients are on anti-Trendelemburg position, the venous return decreases because of the remaining blood on the inferior extremities.

In healthy patients hemodynamic stability use to be maintained, just with the exception of hemorrhage, which can suddenly decompensate that stability. It's highly recommended the pre- hydration of the patient with $500-1000 \mathrm{ml}$ of saline solution before the beginning pneumoperitoneum. Patients that underwent intestinal cleaning use to suffer a loss of liquids, which shows up when they are positioned on anti-Tredelmburg, combined with the pneumoperitoneum and the vasodilators effects of the anaesthetic drugs.

When laparoscopic surgery is performed on the inferior abdomen, like in gynecology or pelvic surgeries, Trendelemburg position is required; it increases the venous return and compensates blood loss. However, heart patients can dramatically increase the cardiac preload. Moreover, the respiratory changes produced by the diaphragm's elevation, caused by an excessive intra abdominal pressure on Trendelemburg position, will raise intra thoracic pressure. That fact, in combination with the higher inspiratorty pressures required, will increase the cardiac impedance, or in other words the cardiac after load; At least four renal insufficiency cases have been described associated with an increase of the intra abdominal pressure due to a post surgery hemorrhage. In contrast with respiratory postoperative complications, hemodynamic complications don't seem to increase with surgery duration.

\section{Respiratory alterations in laparoscopic surgery}

Pathological respiratory changes occurring during laparoscopic surgery are induced by the pneumoperitoneum and the patient position (Trendelemburg or anti Trendelemburg). 
The rise of the intra abdominal pressure elevates the diaphragm, decreasing that way the intra thoracic volume and interfering with the ventilation mechanisms. Those changes will be increased by the Trendelemburg position.

A maximum pressure of $10-15 \mathrm{mmHg}$ is recommended because respiratory alterations are well tolerated on that level. Over $15 \mathrm{mmHg}$ an airway pressure increase occurs together with a rise of the intra thoracic pressure, those changes compress the great and small vessels and initially show up with tachycardia and hypertension, but can produce tachycardia, hypotension and a lower cardiac output at higher pressures.

Many gases can be use to create the pneumoperitoneum, such as Helium, Argon or even nitrogen dioxide, but $\mathrm{CO}_{2}$ still the most used. The phisyopathological alterations produced by the carbon dioxide are in relationship with the amount of gas insufflated and the insufflation's time (Surgery duration).

Pneumoperitoneum decreases thoracopulmonary compliance. Compliance is reduced by $30 \%$ to 50\% in healthy (Bardoczy et al., 1993; Hirvonen et al., 1995; Kendall \& Bhatt., 1995; Oikkonen \& Tallgren., 1995; Fahy et al., 1995; Fahy et al., 1996; As cited in Miller's Anesthesia 2005), obese (Dumont et al., 1997; Casati et al., 2000; Sprung et al., 2002; As cited in Miller's Anesthesia 2005), and American Society of Anesthesiologists (ASA) class III or IV patients, but the shape of the pressure-volume loop does not change. After the pneumoperitoneum is created and kept constant, compliance is not affected by subsequent patient tilting (Rauh et al., 2001; As cited in Miller's Anesthesia 2005) or by increasing the minute ventilation required to avoid intraoperative hypercapnia. Reduction in functional residual capacity due to elevation of the diaphragm (Mutoh et al., 1992; As cited in Miller's Anesthesia 2005) and changes in the distribution of pulmonary ventilation and perfusion from increased airway pressure can be expected. However, increasing IAP to $14 \mathrm{mmHg}$ with the patient in a 10 to 20 degree head up or head down position does not significantly modify physiologic dead space or shunt in patients without cardiovascular problems (Tan et al., 1992; Bures et al., 1996; OdebergWernerman \& Sollevi., 1996; As cited in Miller's Anesthesia 2005).

$\mathrm{CO}_{2}$ spreads in to the blood and it's eliminated during the expiration. But it's also accumulated in the fat tissue and muscle, which explains the high carbon dioxide expirated rate during some minutes after the end of insufflation.

Many works have been published to evaluate the increase in the carbon dioxide arterial pressure $\left(\mathrm{PaCO}_{2}\right)$ during laparoscopic surgery, and it have been shown that in ASA I patients with constant minute volume mechanical ventilation have an average increase in $\mathrm{PaCO}_{2}$ from 4.5 to $10 \mathrm{mmHg}$ in conventional procedures. It has also been shown that in ASA II and ASA III patients the death space is bigger, so the reliability of the carbon dioxide measurement it's lower and the increase in $\mathrm{PaCO}_{2}$ can be misdetected by capnography. In $\mathrm{PaCO}_{2}$ rises above $14 \mathrm{mmHg}$ associated with acidosis, which are not resolved with a $20 \%$ minute volume increase, use to require the transformation of laparoscopic surgery in to open surgery.

The high diffusion of $\mathrm{CO}_{2}$ can originate gaseous embolism, suspicious sigs are the usual ones: Third sound auscultation, expirated $\mathrm{CO}_{2}$ reduction, arterial pressure decrease, increase of the pulmonary vascular resistance, arrhythmia and finally right heart failure.

Capnography and pulse oximetry provide reliable monitoring of $\mathrm{PaCO}_{2}$ and arterial oxygen saturation in healthy patients and in the absence of acute intraoperative disturbances (Bures et al., 1996; Nyarwaya et al., 1994; Baraka et al., 1994; As cited in Miller's Anesthesia 2005). There is a lack of correlation between $\mathrm{PaCO} 2$ and end-tidal carbon dioxide tension $\left(\mathrm{PEtCO}_{2}\right)$ in sick patients, particularly those with impaired $\mathrm{CO}_{2}$ excretion capacity, and otherwise in healthy 
patients with acute cardiopulmonary disturbances. Arterial blood sampling is recommended when hypercapnia is clinically suspected, even in the absence of normal $\mathrm{PEtCO}_{2}$.

In summary, during $\mathrm{CO}_{2}$ pneumoperitoneum, the increase of $\mathrm{PaCO}_{2}$ may be multifactorial: absorption of $\mathrm{CO} 2$ from the peritoneal cavity; impairment of pulmonary ventilation and perfusion by mechanical factors such as abdominal distention, patient position and volumecontrolled mechanical ventilation; And also a depression of ventilation by premedicant and anaesthetic agents in the case of spontaneous breathing (Table 1).

\begin{tabular}{|c|c|}
\hline \multicolumn{2}{|c|}{ 1.- $\mathrm{CO}_{2}$ Absortion from the peritoneal cavity. } \\
\hline 2.- Ventilation / perfusion mismatch: increase dead space. \\
\hline $\begin{array}{c}\text { - Abdominal distension. } \\
\text { - Possition of the patient. }\end{array}$ & $\begin{array}{c}\text { (e.g., steep tilt) } \\
\text { - Reduced cardiac output. }\end{array}$ \\
\hline All these mechanisms are accentuated in sick patients (e.g., Obese, ASA II or III) \\
\hline 3.- Increased metabolism. (e.g., insufficient plane of anesthesia) \\
\hline 4.- Depression of ventilation by anaesthetics. (e.g., spontaneous breathing) \\
\hline \multicolumn{2}{|c|}{ 5.- Accidental events. } \\
\hline - $\mathrm{CO}_{2}$ emphisema (i.e., subcutaneous or body cavities). \\
- Capnothorax. \\
$-\mathrm{CO}_{2}$ embolism (Selective bronchial intubation)
\end{tabular}

Table 1. Causes of increased $\mathrm{PaCO}_{2}$ during laparoscopy procedures (Miller, 2005).

\subsection{Carbon dioxide subcutaneous emphysema}

$\mathrm{CO}_{2}$ subcutaneous emphysema can develop as a complication of accidental extraperitoneal insufflation (Hall et al., 1993; As cited in Miller's Anesthesia 2005) but can also be considered as an unavoidable side effect of certain laparoscopic surgical procedures that require intentional extraperitoneal insufflation, such as inguinal hernia repair, renal surgery, and pelvic lymphadenectomy (Mullet et al., 1993; Wolf et al., 1995; As cited in Miller's Anesthesia 2005). During laparoscopic fundoplication for hiatal hernia repair, the opening of the peritoneum overlying the diaphragmatic hiatus allows passage of $\mathrm{CO}_{2}$ under pressure through the mediastinum to the cervicocephalic region. In these three circumstances, $\mathrm{VCO}_{2}$, $\mathrm{PaCO}_{2}$ and $\mathrm{PEtCO}_{2}$ increase (Mullet et al., 1993; As cited in Miller's Anesthesia 2005). Any increase in $\mathrm{PEtCO}_{2}$ occurring after $\mathrm{PEtCO}_{2}$ has plateaued should suggest this complication.

\subsection{Pneumothorax, pneumomediastinum and pneumopericardium}

Movement of gas during the creation of a pneumoperitoneum can produce pneumomediastinum (Spielman et al., 1989; As cited in Miller's Anesthesia 2005), unilateral and bilateral pneumothorax (Whiston et al., 1991; As cited in Miller's Anesthesia 2005), and pneumopericardium (Knos et al., 1989; As cited in Miller's Anesthesia 2005). Defects in the diaphragm or weak points in the aortic and esophageal hiatus may allow gas passage into the thorax. Pneumothorax may also develop from pleural tears during laparoscopic surgical procedures at the level of the gastroesophageal junction (e.g.,fundoplication for hiatal hernia). Pneumothorax during fundoplication is more frequently located on the left side. These complications are potentially serious and may lead to respiratory and hemodynamic disturbances. Capnothorax reduces thoracopulmonary compliance, and airway pressures increase. $\mathrm{VCO}_{2}, \mathrm{PaCO}_{2}$ and $\mathrm{PEtCO}_{2}$ also increase (Joris et al., 1995; As cited in Miller's 
Anesthesia 2005). Diagnosis must be confirmed by auscultation of the chest and roentgenography.

When capnothorax develops during laparoscopy, we follow several guidelines (Joris et al., 1995; As cited in Miller's Anesthesia 2005).

- $\quad$ Stop $\mathrm{CO}_{2}$ administration.

- Adjust ventilator settings to correct hypoxemia.

- Apply positive end-expiratory pressure (PEEP).

- $\quad$ Reduce IAP as much as possible.

- Maintain close communication with the surgeon.

- Avoid thoracocentesis unless necessary, because pneumothorax spontaneously resolves after exsufflation.

\section{Changes related to patient positioning}

The patient positioning on the surgery table for laparoscopic procedures must follow the same general principles than in any other surgery under general anesthesia. Hemodynamic situations leading to hypo perfusion can occur during the procedures, which can affect skin areas compressed over rigid elements. Must be considered as a general rule, that laparoscopic procedures are usually longer than open surgery procedures, so the deleterious elements will be acting more time.

The most vulnerable areas to friction or bad positioning must be protected firstly (Cornea and conjunctiva, lips, tongue and penis). It's useful to ask the patient to stay in the surgery position before the deep sedation, to indicate the anesthesiologist where does he feel uncomfortable or slight pain in order to correct the position or to protect that areas.

During the patient positioning it's also recommended to take special care of the electrosurgical scalpel plate or any other electrical device close to the patient. If the plate is not properly placed attached to the skin, the patient would be in risk of burn injuries.

When the patient is positioned in lateral recumbency perfusion is higher in the lower lung, but ventilation is more effective in the upper lung, that's because of the functional residual capacity (FRC) present in every anesthetized patient. The diaphragm relaxation leads to the lost of the inspiration's favorable curve; the abdominal mass pressures the lower lung in relaxed patients and the pressure is also transmitted to the mediastinum, contributing to reduce the FRC.

In summary, the ventilation perfusion quotient will be altered and reduced. In this case, positive end expiratory pressure (PEEP) will elevate the lower lung in to a better position at the volume-pressure curve, increasing the FRC and reestablishing the initial values.

All these are general factors to keep in mind during any laparoscopic procedure, but there are specific factors to be considered depending on the particular procedure. The specific factors are mainly related with the required patient's position: Upper abdomen procedures, lower abdomen procedures, hysteroscopy and urologic procedures.

\subsection{Upper abdomen procedures}

In upper abdomen laparoscopic procedures the patient use to be positioned in different anti Trendelemburg degrees, besides it favors ventilation by descending diaphragm and requires lower inspiratory pressures, it causes a reduction in the venous return and therefore in the cardiac output that can reach a $50 \%$. A young and healthy patient can compensate it by increasing the heart rate and vascular resistances, avoiding the apparition of hypotension. 
But in elderly patients or patients with systemic disease the compensation mechanisms may not be that effective and hypotension or even heart collapse can occur.

Those hemodynamic alterations can be extreme in patients presenting dehydration, when myocardial depressing drugs or vasodilator drugs are used (High propofol dosage, halogenated drugs) and in cases when excessive intra-abdominal pressure compress the cava vein (Lew et al., 1992).

Hypotension has also a pulmonary shunt effect that impairs $\mathrm{CO}_{2}$ elimination promoting hypercapnia's cardiovascular effects. Anti-Trendelemburg position favors gas embolism and its consequences (Rock \& Brown, 1994; Soper, 1994).

\subsection{Lower abdomen procedures}

In lower abdomen procedures (pelvic gynecology) Trendelemburg position is used, sometimes in a exaggerated degree, like in pelvic laparoscopy. That makes ventilatory condition worse, but improves venous return and increase cardiac output in healthy patients. Fortunately most of the gynecology procedures made in marked Trendelemburg position and performed in healthy young patients. However, in patients with low cardiac reserve, that CO increase can even produce a heart failure. When lithotomic position is associated, like in pelvic gynecology or intestinal procedures, the rise in the venous return is higher.

A long and pronounced Tendelemburg, together with the intra abdominal pressure can produce a reflex tachycardia that may be caused by the development of a moderate cerebral edema. Maintenance of this position requires shoulder holders, and if they are not properly placed produce brachial plexus lesions, especially when associated with arm abduction and rotation.

When arms are placed against the body during all the procedure, which can be long, intravenous catheter mast be protected, anaesthetic monitoring probes must be ensured, as well as fingers or any other part susceptible of being pinch or stocked if position changes are needed.

During procedures, surgeon's assistants must hold optics and instruments during long periods of time, which make them lean on the patient. It's the anesthesiologist responsibility to avoid that it hurts the patient.

\subsection{Hysteroscopy and urologic procedures}

On those two groups of interventions the positions used are the dorsal decubitus and the lithotomy position, which don't use to cause any hemodynamic or respiratory alterations, just with the exception of extremely obese patients. But in transurethral resections or hysteroscopy procedures the irrigation solution can pass in to the intra vascular space or abdominal cavity, if urinary bladder or uterus respectively is perforated. That's the reason to have a good monitoring and take some precautions like: limiting the resection time to one hour, limiting the height of the irrigation bags to 1.2 meters, checking patient's clinical symptoms (for this the patient use to be awake with loco regional anesthesia), being careful with the abdominal distension and checking often the liquid balance (incomes and outcomes).Hypothermia used to be a complication in that surgeries, but it's avoided by monitoring patient's temperature and using warm intravenous and irrigation liquids.

\subsection{Positioning nerve injury}

Neural enlargement must be prevented in order to avoid neurapraxia. Arm's abduction and external rotation, extreme hip abduction and knees in lithotomic position can all produce 
neuropathies, despite they are transitory, they require a neurological examination, rehabilitation and postoperative care that can be avoided by prevention. It must be kept in mind that neuromuscular blockade lead to unnatural stances. (Kaplan \& Rogers, 1994)

To prevent the nervous compression we must take a special care of the areas where nerves pass close beneath the skin, like the elbow, the knee, the feet or the face. The typical nervous lesion produced during the anesthesia on the brachial plexus and the lower extremities nerves are typically by combination of two mechanisms: Bony compression and enlargement.

\section{Monitoring}

Laparoscopic surgery is associated with a better postoperative condition (Less pain, less time to heal wounds) making the back to normal life easier to patients, but that doesn't mean a decrease in intra operative stress, especially in patients with systemic diseases. The monitoring techniques and its characteristics are the same as for open surgeries.

\subsection{ASA I and II patients monitoring}

Minimal standard monitoring includes: ECG, non invasive arterial pressure, auscultation, pulse oxymetry, temperature and oxygen concentration. Ventilatory monitoring is always essential (volumes, inspiratory pressure, oxygen concentration).

The ECG value is higher if it's possible to monitoring two derivations at the same time: DII for detecting arrhythmia and V5 lead to be able to detect ischemia.

It's highly recommendable to check often the non invasive arterial pressure devices, because they use to be positioned in the arm, and surgeon movements or changes in patient position can originate false data from the devices.

End-tidal concentration of carbon dioxide $\left(\mathrm{EtCO}_{2}\right)$ it's a part of standard monitoring in regular surgery, but it is essential in laparoscopy procedures. $\mathrm{EtCO}_{2}$ determination help's in controlling the $\mathrm{CO}_{2}$ absorption-elimination equilibrium. In healthy patients, the $\mathrm{EtCO}_{2}$ is correlated with the $\mathrm{PaCO}_{2}$ from 4 to $8 \mathrm{mmHg}$, but this gradient can be increased in shock or increased dead space cases. Any deep fall of $\mathrm{EtCO}_{2}$ must make us think about an embolism, hypotension or heart collapse. Intra abdominal pressure and $\mathrm{CO}_{2}$ absorption obliges the anesthesiologist to make ventilation adjustments in order to guarantee carbon dioxide elimination. The $\mathrm{EtCO}_{2}$ allows these maneuvers to be quick and safe when changes appear. (Fig.2)

The shape of the capnography wave gives a lot of additional information about the patient's physiologic status. The diagnoses of a gas embolism or an intra operative bronchospasm are facilitated by the observation of $\mathrm{EtCO}_{2}$.

During one lung ventilation, if alveolar ventilation remains the same, the $\mathrm{EtCO}_{2}$ doesn't changes significantly and still keeping a good correlation with $\mathrm{PaCO}_{2}$.

It's essential to control patient's temperature, because hypothermia is a danger in long procedures due to irrigation fluids, and the anesthesia recovery will be more soft and quick if hypothermia has been avoided.

The $\mathrm{EtCO}_{2}$ and temperature allow the anesthesiologists to detect estrange but possible complications like malignant hyperthermia.

High inspiratory pressures on the ventilator can change the intra thoracic dynamic and cardiovascular function, but it can also create a piston like movement of the tracheal tube causing pharyngeal discomfort and changes in the voice tone that can be a problem during patient's recuperation process. 


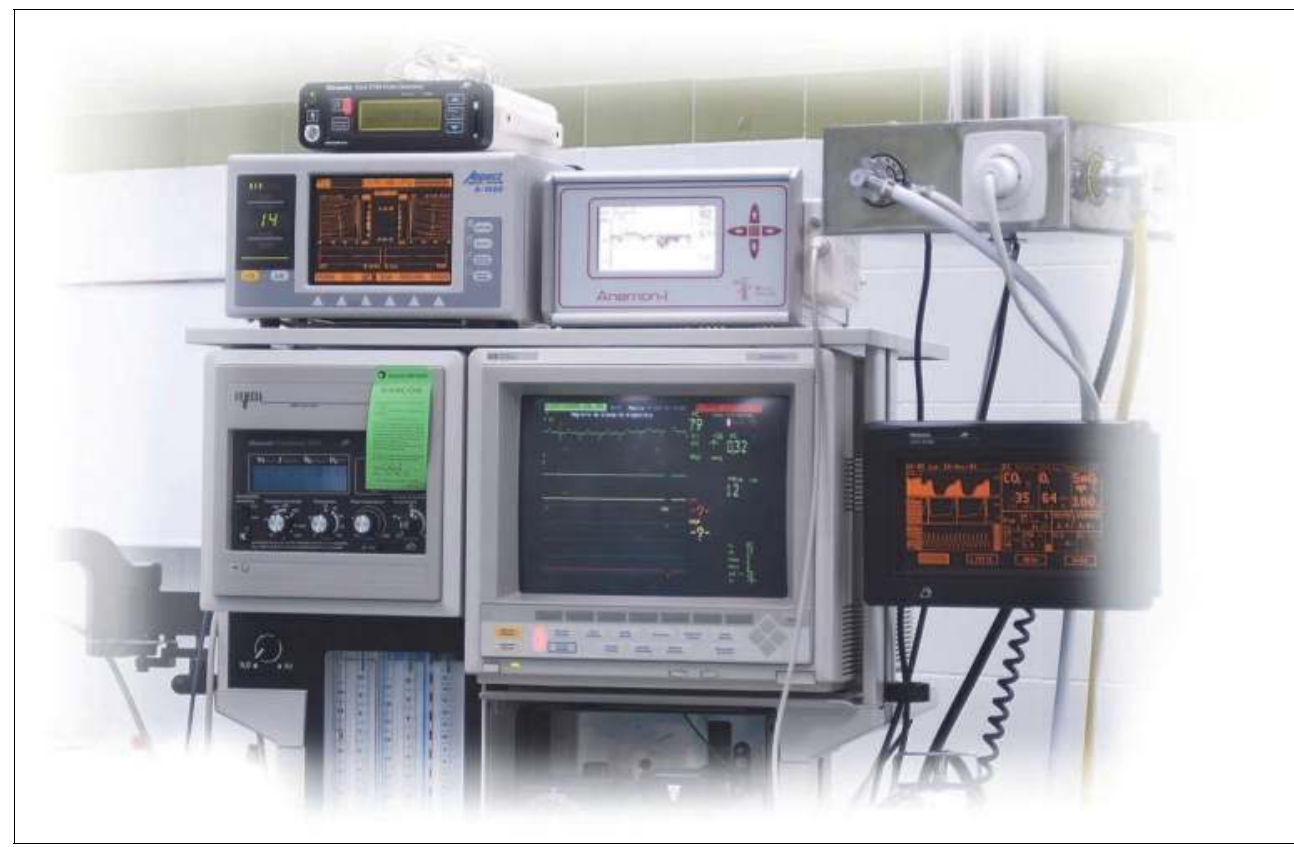

Fig. 2. Anesthetic monitoring during laparoscopic surgery.

Subcutaneous emphysema is always a laparoscopy associated risk. That makes mandatory to examine the patient for emphysema at the cervical, thorax and abdomen areas after surgery. It's also recommended to perform thorax radiography to rule out possible pneumothorax or pneumomediastinum complications.

\subsection{ASA III, IV and V patients monitoring}

There are no general rules regarding monitoring of systemic disease patients. Depending on the previous cardiovascular and respiratory status and depending on the expected complications as well, different techniques will be added to the standard monitoring.

There are no fixed rules about the use of the invasive arterial pressure monitoring, but it gives valuable information in every heart beat. That makes it very useful, considering also its low morbidity. On patients suffering heart disease, hypertension cases and or when important intravascular volume changes are expected, the arterial pressure value and its curve shape are essential.

Patients suffering ischemic myocardial injury or under arrhythmia risk are also ideal candidates to establish an invasive arterial pressure monitoring, same as morbid obesity patients where the non invasive measurements can be inexact. During thoracoscopy procedures with compression or distortion of the mediastinum structures risk, arterial pressure monitoring must be present to be able to detect the consequences of these compressions.

On patients with lung disease it's convenient to establish frequently a $\mathrm{PaCO}_{2}-\mathrm{EtCO}_{2}$ gradient because the elimination can be impaired. Arterial catheterization provides a source for arterial blood gasometry (ABG). 
The Central venous pressure (CVP) monitoring is the most widely used method to determine and treat intravascular volume loss, but its use in laparoscopic procedures is controversial. The increased intra abdominal and intra thoracic pressure can interfere and cause false readings. When laparoscopy is performed in upper abdomen in anti Trendelemburg position CVP monitoring is use full, even knowing that the readings may be false, the tendency $\mathrm{r}$ orientates to address the consequences of the volume alterations. Anyway low intravascular volume changes are produced in laparoscopic procedures.

The pulmonary artery catheterization allows estimating the ventricular after load by determining the pulmonary capillary pressure or pulmonary artery occlusion pressure; it also allows performing a complete hemodynamic study and managing the hemodynamic treatment. Its advantages are controversial, but in many anesthesiologist opinions it is very useful to manage patients with left ventricle disease, severe ischemic myocardial disease, hypertrophic myocardial disease, sub aortic idiopathic hypertrophic stenosis or pulmonary hypertension. The pulmonary artery catheter in one lung ventilation patients during thoracoscopic procedures has limitations, because it can be placed on the collapsed lower lung and don't reflect directly the left ventricle pressure. On the other hand, it results essential in heart diseases patients that to be able to stand the one lung ventilation and the pneumothorax, because they need to be treated with pre load increases and/or with ionotropic drugs.

Transesophageal ECG allows an early diagnosis when monitoring heart function and ischemia, more early than pulmonary artery catheterization. However it requires an uncommon high experience level to be useful.

\section{Systemic disease patients}

Different precautions must be taken in systemic disease patients depending on the particular disease.

\subsection{Heart disease}

The selection criteria for heart disease patient are multiple. It's important to remember that heart disease patients don't have to proposed to laparoscopic procedures just with the pretext of the lower postoperative care required, because that have been proved true just in healthy patients. Because of that reason, heart disease patient need to be managed by experienced anesthesiology teams. The hypertension risk, the hemorrhage risk after improper homeostasis and the hemodynamic modifications caused by the insufflation can derivate in to life-threatening complications easily on those patients.

It must be remembered that patients having a pacemaker should be treated with special care because monopolar electrosurgical scalpel can interfere with it. Plate must be placed properly and with caution, and heart mechanical activity should be monitored. In a surgery team with a good knowledge of technical equipment selection criteria can be different and only determinate by hemodynamic modifications risks.

It's prudent to reject patients with severe alterations of diastolic function on congestive heart failure. Controlled arterial hypertension or stabilized coronary insufficiencies are not considered contraindication, but it's basic to have them under control before surgery in order to decrease the perioperative mortality.

Cardiovascular complications incidence doesn't differ from open surgery procedures. An important factor is the perioperative cardiovascular monitoring in order to detect and treat any complication presented. 


\subsection{Respiratory disease}

Respiratory complications after laparoscopic surgery are significantly lower than open surgery (Rose, 1992; Rothwell et al., 1992; Schwed et al., 1992).

Positioning and intra peritoneal pressures raise alveolar death space; witch can be already increased by diseases like in obstructive bronchopneumonia. The $\mathrm{EtCO}_{2}$ contributes to underestimate the $\mathrm{PaCO}_{2}$ in patients suffering chronic respiratory insufficiencies if we compare with healthy ones. A $20 \%$ of the intra peritoneal hypertension is transmitted to the thorax during controlled ventilation procedures, that fact increases the respiratory airways pressures, what is so harmful to patients suffering bullous emphysema.

The postoperative respiratory benefits it's a very important factor to keep in mind when indicating a laparoscopic procedure to patients suffering chronic respiratory insufficiency, because during postoperative period exists a lower diminution of the pulmonary volumes with a lower diaphragm dysfunction limited to the posterior region (Rothwell et al., 1992). A quicker recovery of pulmonary function is developed during postoperative period (Putensen-himer et al., 1992; Shear et al., 1992; Armengaud et al., 1992; Cooney et al., 1992; Mahul et al., 1992) achieving normal spirometry values in 72 hours in comparison with the 8 days that it takes to recover from laparotomy procedures. Those times are both increased in elderly patients.

Thoracoscopic procedures are recommended in patients suffering restrictive respiratory insufficiency without a significant increase in airways pressure. In patients suffering bullous emphysema and obstructive chronic respiratory insufficiencies insufflation pressures must be reduced as much as possible. Any serious respiratory complication like pneumothorax should stop the surgery. Recuperation must be smooth, avoiding tremors and agitation that may increase oxygen consumption. Anesthesia is maintained until an acceptable $\mathrm{PaCO}_{2}$ is reached comparing with preoperative values; extubation is performed when early signs of tube rejection are observed.

\subsection{Pregnant patients}

Laparoscopy is the most common surgery performed on the first semester of pregnancy (Mazze \& Källen, 1989) and there are more advanced pregnancy cases described in literature.

The most common nonobstetric surgical procedures during pregnancy are adnexal surgery, appendectomy, and cholecystectomy, and they are amenable to laparoscopic surgery (Visser et al., 2001; As cited in Miller's Anesthesia 2005).Laparoscopy during pregnancy raises several concerns. Abdominal surgery increases the risk of miscarriage or premature labor. However, all the reports in the literature of laparoscopy carried out between 4 and 32 weeks of estimated gestational age have resulted in uncomplicated pregnancies (Lemarie \& van Erp, 1997; Affleck et al., 1999; Barone et al., 1999; As cited in Miller's Anesthesia 2005).

The effects of increased IAP and hypercapnia on the human fetus were also investigated. $\mathrm{CO}_{2}$ pneumoperitoneum induced significant fetal acidosis. Fetal heart rate and arterial pressure increased, but these changes were minimal (Hunter et al., 1995; As cited in Miller's Anesthesia 2005).

Hemodynamic changes induced by pneumoperitoneum are similar in pregnant and nonpregnant women (Steinbrook \& Bhavani-Shankar, 2001; As cited in Miller's Anesthesia 2005).The following recommendations (Lemarie \& van Erp, 1997; As cited in Miller's Anesthesia 2005)are for safe laparoscopy in pregnant patients: 
1. The operation should occur during the second trimester, ideally before the $23^{\text {rd }}$ week of pregnancy, to minimize the risk of preterm labor and to maintain an adequate intraabdominal working room.

2. Tocolytics are beneficial to arrest preterm labor, but their prophylactic use is debatable.

3. Open laparoscopy should be used for abdominal access to avoid damaging the uterus.

4. Fetal monitoring may be performed using transvaginal ultrasonography.

5. Mechanical ventilation must be adjusted to maintain a physiologic maternal alkalosis.

\subsection{Laparotomy}

Patients that recently underwent laparotomy surgery or patients that have suffered peritonitis used to be considered as non indicated patients. Nowadays those conditions are not considered contraindicated anymore, but special care must be taken, especially regarding ectopic insufflation.

\subsection{Urological disease}

There are some indications in urology laparoscopies, like in other medical specialties, perfectly known and accepted coexisting with others that still need to be accepted.

Varicocele treatment has the advantage of avoiding postoperative pain, facilitating the back to normal active life in young patients.

\subsection{Obesity}

Morbid obesity has respiratory and cardiovascular risks that need to be addressed and controlled during laparoscopic surgeries. The Palmer needle and trocar insertion can be difficult, requiring the use of an open laparoscope, what increases the risk of carbon dioxide diffusion in the peritoneum. Moreover, the weight of the abdominal wall is an important factor increasing the abdominal pressure. The most important benefits for these patients are: the quick recovery, the decrease of thromboembolism risk and the early alimentation begin after surgery (Bromberg et al., 1992).

\subsection{Glaucoma}

The intra abdominal pressure rise is accompanied by an intraocular pressure rise, which is increased by Trendelemburg position (Hvidbreg et al., 1981) but is not always harmful in short periods of time. Laparoscopy is totally contraindicated in closed angle glaucoma patients.

\subsection{Intracraneal hypertension}

Insufflation and Trendelemburg positioning contribute to increase intracranial rise. Laparoscopic procedures are contraindicated in patients suffering important and acute (traumatic, tumor, hydrocephalus) cranial hypertension. Pharmacological treatment or temporal shunting can be performed to control the hypertension. If a recent ventriculoperitoneal shunt has been performed there is no contraindication because a non return valve is present. The leakage tests of these valves are not totally reliable when they are suspended in cephaloraquideum liquid. A diffusion of carbon dioxide occurs along the subcutaneous way of the valve (Schwed et al., 1992).Cerebral and retinal vascular accidents can occur. 


\section{Summary}

Advantages derived from laparoscopic surgeries are multiple and well know: Minimal trauma is produced; it reduces postoperative pain and provides a quicker recovery shortening the hospital stay. Pneumoperitoneum induces intraoperative cardiorespiratory changes. $\mathrm{PaCO}_{2}$ increases because of $\mathrm{CO}_{2}$ absorption from the pneumoperitoneum. In systemic disease patients, cardiorespiratory disturbances aggravate this increase in $\mathrm{PaCO}_{2}$. Improved knowledge of the pathophysiologic hemodynamic changes in healthy patients allows for successful anaesthetic management of cardiac patients, by optimizing preload before pneumoperitoneum and through judicious use of vasodilating drugs. Alternative insufflation gases don't seem to reduce hemodynamic changes; gasless laparoscopy is more helpful in that concern, but unfortunately increases technical difficulty. General anaesthesia with controlled ventilation seems to be the best technique for operative laparoscopy. The knowledge of the pathophysiologic changes occurring during pneumoperitoneum allows a safe management of the patients, even in those with systemic disease or cardiorespiratory complications.

\section{Key points}

The most remarkable facts regarding anaesthesia in laparoscopic procedures are (Miller, 2005):

- $\mathrm{CO}_{2}$ pneumoperitoneum results in ventilatory and respiratory changes. Pneumoperitoneum decreases thoracopulmonary compliance. $\mathrm{PaCO}_{2}$ increases $(15 \%$ to $25 \%$ ) by $\mathrm{CO}_{2}$ absorption from the peritoneal cavity. Capnography reliably reflects this increase, which plateaus after 20 to 30 minutes.

- In compromised patients, cardiorespiratory disturbances aggravate the increase in $\mathrm{PaCO}_{2}$ and enlarge the gradient between $\mathrm{PaCO}_{2}$ and $\mathrm{EtCO}_{2}$.

- Any increase in $\mathrm{EtCO}_{2}$ larger than $25 \%$ and/or occurring later than 30 minutes after the beginning of peritoneal $\mathrm{CO}_{2}$ insufflation should suggest $\mathrm{CO}_{2}$ subcutaneous emphysema, the most frequent respiratory complication during laparoscopy.

- Peritoneal insufflation induces alterations of hemodynamics, characterized by decreases of cardiac output, elevations of arterial pressure, and increases of systemic and pulmonary vascular resistances. Hemodynamic changes are accentuated in high-risk cardiac patients.

- The pathophysiologic hemodynamic changes can be attenuated or prevented by optimizing preload before pneumoperitoneum and by vasodilating agents, $\alpha_{2}-$ adrenergic receptors antagonists, high doses of opioids, and $\beta$-blocking agents.

- Similar pathophysiologic changes occur during pregnancy and in children. Laparoscopy can be safely managed in pregnant women before the $23^{\text {rd }}$ week of pregnancy provided by that hypercapnia is prevented. The open laparoscopy approach should be considered to avoid damaging the uterus.

- Gasless laparoscopy may be helpful to reduce pathopysiologic changes induced by CO2 pneumoperitoneum but unfortunately increases technical difficulty.

- Laparoscopy results in multiple postoperative benefits allowing for quicker recovery and shorter hospital stay. These advantages explain the increasing success of laparoscopy, which is proposed for many surgical procedures.

- Improved knowledge of the intraoperative repercussions of laparoscopy permits safe management of patients with more and more severe cardiorespiratory disease, who may subsequently benefit from the multiple postoperative advantages offered by this technique. 


\section{References}

Armengaud MH, Pipien J, Trevoux-Paul J, Alexandre JH, Cousin MT. Fonction pulmonaire après cholécystectomie par laparoscopie. Annales Françaises d'Anesthésie et de Réanimation. 1992; 11:R84

Bromberg N, Matuszak JP, Delecluze Ph, Atat I, Prevot JM, Krivosic-Horberor. Fonction pulmonaire après cholécystectomie par voie laparoscopique chez l'obèse. Ann Fr Anesth Réanim 1992;11:R20

Carrasco MS, Gomar C, Jiménez MJ, Martín MF \& Lima JR. Consideraciones anestésicas en la cirugía endoscópica en humanos. In: Carrasco MS, Usón J, eds. Aprendizaje y Aplicación de la Anestesia en Cirugía Toracoscópica. Edika Med. 1998; 132-135

Cooney CM, Lyons JB, Hennigan A, Blunnie WP, Moriarty DC. Ventilatory function following laparoscopic cholecystectomy. (Abstract). Canadian Journal of Anaesthesia. 1992; 39: A54

Hvidberg A, Kessing SV, Fernandes A. Effect of changes in $\mathrm{PCO}_{2}$ and body positions on intraocular pressure during general anaesthesia. Acta Ophthalmologica (Copenhagen). 1981 Aug; 59(4):465-75.

Joris JL, Hamoir EE, Hartstein GM, Meurisse MR, Hubert BM, Charlier CJ \& Lamy ML. Hemodynamic changes and catecholamine release during laparoscopic adrenalectomy for pheochromocytoma. Anesthesia and Analgesia. 1999; 88:16-21.

Kaplan MB, Rogers R. Laparoscopic Surgery: A View From the Head of the Table. Seminars in Laparoscopic Surgery. 1994 Dec; 1(4):207-210.

Lew JK, Gin T, Oh TE. Anaesthetic problems during laparoscopic cholecystectomy. Anaesthesia and Intensive Care. 1992 Feb; 20(1):91-2.

Llagostera-Pujol S, Dilme-Muñoz J, Yeste-Campos M, Escudero-Rodríguez JR \& ViverManresa E. Cirugía laparoscópica del aneurisma abdominal. Angiología. 2002; 54(3):252-258.

Mahul PH, Bou B, El Khoury, Riffat J, Massardier N, Guillot B. Fonction respiratorie et cholécystectomie par coelioscope digestive. Annales Françaises d'Anesthésie et de Réanimation. 1992; 11: R83.

Mazze RI, Källén B. Reproductive outcome after anesthesia and operation during pregnancy: a registry study of 5405 cases. American Journal of Obstetrics and Gynecology. 1989 Nov; 161(5):1178-85.

Miller RD. Miller's Anesthesia, 6th ed. Philadelphia, Elsevier, 2005, p 2287.

Putensen-Himmer G, Putensen C, Lammer H, Lingnau W, Aigner F, Benzer H. Comparison of postoperative respiratory function after laparoscopy or open laparotomy for cholecystectomy. Anesthesiology. 1992; 77(4):675-80.

Rose DK, Cohen MM, Soutter DI. Laparoscopic cholecystectomy: the anaesthetist's point of view. Canadian Journal of Anaesthesia. 1992 Oct; 39(8):809-15.

Rothwell BC, Katagiri M, Young RN, Nixon JA, Easton PA. Costal and crural diaphragm function after laparoscopic cholecystectomy. American review of respiratory disease. 1992; 145:A152

Schwed DA, Edoga JK, McDonnell TE. Ventilatory impairment during laparoscopic cholecystectomy in a patient with a ventriculoperitoneal shunt. Journal of Laparoendoscopic Surgery. 1992; Feb; 2(1):57-9.

Shear JM, Holtmann B, White PF. Pulmonary function following laparoscopic cholecystectomy [abstract]. Anesthesia and Analgesia. 1992; 74: 5286. 


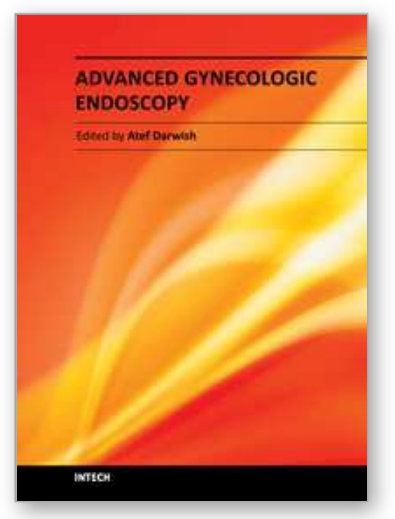

\author{
Advanced Gynecologic Endoscopy \\ Edited by Dr. Atef Darwish
}

ISBN 978-953-307-348-4

Hard cover, 332 pages

Publisher InTech

Published online 23, August, 2011

Published in print edition August, 2011

The main purpose of this book is to address some important issues related to gynecologic laparoscopy. Since the early breakthroughs by its pioneers, laparoscopic gynecologic surgery has gained popularity due to developments in illumination and instrumentation that led to the emergence of laparoscopy in the late 1980's as a credible diagnostic as well as therapeutic intervention. This book is unique in that it will review common, useful information about certain laparoscopic procedures, including technique and instruments, and then discuss common difficulties faced during each operation. We also discuss the uncommon and occasionally even anecdotal cases and the safest ways to deal with them. We are honored to have had a group of world experts in laparoscopic gynecologic surgery valuably contribute to our book.

\title{
How to reference
}

In order to correctly reference this scholarly work, feel free to copy and paste the following:

Maria F. Martîn-Cancho, Diego Celdrán, Juan R. Lima, Maria S. Carrasco-Jimenez, Francisco M. SánchezMargallo and Jesús Usón-Gargallo (2011). Anaesthetic Considerations during Laparoscopic Surgery, Advanced Gynecologic Endoscopy, Dr. Atef Darwish (Ed.), ISBN: 978-953-307-348-4, InTech, Available from: http://www.intechopen.com/books/advanced-gynecologic-endoscopy/anaesthetic-considerations-duringlaparoscopic-surgery

\section{INTECH}

open science | open minds

\author{
InTech Europe \\ University Campus STeP Ri \\ Slavka Krautzeka 83/A \\ 51000 Rijeka, Croatia \\ Phone: +385 (51) 770447 \\ Fax: +385 (51) 686166 \\ www.intechopen.com
}

\author{
InTech China \\ Unit 405, Office Block, Hotel Equatorial Shanghai \\ No.65, Yan An Road (West), Shanghai, 200040, China \\ 中国上海市延安西路65号上海国际贵都大饭店办公楼 405 单元 \\ Phone: +86-21-62489820 \\ Fax: +86-21-62489821
}


(C) 2011 The Author(s). Licensee IntechOpen. This chapter is distributed under the terms of the Creative Commons Attribution-NonCommercialShareAlike-3.0 License, which permits use, distribution and reproduction for non-commercial purposes, provided the original is properly cited and derivative works building on this content are distributed under the same license. 